\title{
Appraising Computing Self-Efficacy Emotions across a 5-Week Multimedia Authoring Project
}

\author{
C. A. DeCoursey ${ }^{1} \&$ C. Bernal Sati ${ }^{1}$ \\ ${ }^{1}$ Department of Humanities, AL Faisal University, Riyadh, Kingdom of Saudi Arabia \\ Correspondence: C. A. DeCoursey, Department of Humanities, AL Faisal University, Al Zahrawi Street, Al \\ Maather, Al Takhassusi Road, Riyadh, 11533, Kingdom of Saudi Arabia. Tel: 966-1-12-7378. E-mail: \\ decourseyca@yahoo.com
}

Received: March 9, 2016

Accepted: April 19, $2016 \quad$ Online Published: May 5, 2016

doi:10.5539/ijps.v8n2p95

URL: http://dx.doi.org/10.5539/ijps.v8n2p95

\begin{abstract}
Emotion is a key aspect of how non-specialists learn computing. The emotions included in Computing Self-Efficacy (CSE) research were identified prior to the emergence of recent models of emotion. There has been no attempt to inventory attitudes elicited while learning computing, using contemporary psycholinguistic models of subjectivity. This study of 58 medical students in Saudi Arabia used Appraisal analysis of weekly written personal responses to gain a comprehensive overview of emotions elicited during five weeks' instruction on website-building. A Before-After Survey identified gains made in reported frequency of tasks performed outside class. A Weekly Attitude Survey identified the strength of 6 previously-identified CSE emotions, framed as positive-negative pairs. Participant journals showed that many emotions included in previous CSE emotions are not frequently-realised, and attitudes are changeable across the learning process. Overall, most positive-negative pairs do not behave correlatively, some persist where others progress, and incidence is a better guide than polarity to an attitude's significance. Capacity and confidence suggest three stages in learning a computing task.
\end{abstract}

Keywords: appraisal analysis, computer self-efficacy, emotion, medical education, Saudi Arabia, systemic functional linguistics, website building

\section{Introduction}

Computing is essential to most workplace tasks we do today. Most people have to learn new computing tasks periodically, though they are not computing specialists. This evokes a range of responses, positive and negative, many of which have been studied. Recent models of emotion have not yet been applied to studies of Computer Self-Efficacy (CSE). Corpus-based psycholinguistic methods offer semantically fine-grained tools for identifying and analysing what non-specialists choose to articulate about the experience of learning new computing tasks. This study of medical students in the Kingdom of Saudi Arabia (KSA) explored attitudes evoked while learning to build a website.

Self-efficacy refers to actions undertaken by learners in support of learning, including seeking help, rehearsing information, organising materials, and monitoring ongoing performance (Bandura, 2006). Students' beliefs about their own self-regulation shapes their interest in and persistence with new tasks (Schuck \& Ertmer, 2000). Academic self-efficacy refers to students' abilities to set goals, monitor progress, self-test and self-correct, in order to achieve academic goals (Bong \& Skaalvik, 2003). Emotion interacts with the elements of academic self-efficacy (Bandura, Caprara, Barbaranelli, Gerbino, \& Pastorelli, 2003; Caprara, Vecchione, Alessandri, \& Barbaranelli, 2011). Learning evokes enjoyment, pride, anxiety, relief and boredom (Pekrun, Goetz, Titz, \& Perry, 2010). Emotions evoked when learners face new tasks reflect past experiences and emotions (Chen, Gully, Stanley, Whiteman, \& Robert, 2000).

CSE refers to self-regulatory actions undertaken by computing nonspecialists, including their beliefs about their CSE (Hasan, 2003) and the emotions evoked by computing tasks (Coffin \& Mackintyre, 2000). These subjective attitudes shape their CSE outcomes (Torkzadeh, Plfughoeft, \& Hall, 1999). Previous CSE studies have identified emotion as a crucial aspect of CSE, using psychometric scales for attitudinal polarity, and correlating positive and negative responses to various states and beliefs, and to gender (Bandura, 1997; Beckers \& Schmidt, 2001; Torkzadeh \& Van Dyke, 2002). While polarity is a basic dimension of emotion, psycholinguistics now offers delicate methods taxonomising emotion into semantic subcategories (Kousta, Vinson, \& Vigliocco, 2009). 
Medical students comprise a relevant study group, as their academic self-efficacy and computing exposure are high (Artino, La Rochelle, \& Durning, 2010).

Some CSE emotions have been extensively researched. Anxiety (Venkatesh, 2000) reflects related states such as confidence (Garland \& Noyes, 2008), and self-beliefs about capability (Compeau \& Higgins, 1985; Bandura, 1986). Other well-researched CSE states include satisfaction (Bhattacherjee, 2001), and how easy nonspecialists find computing tasks (Saade \& Kira, 2009). Recent research has explored intrinsic CSE emotions, including enjoyment and frustration (Bessière, Newhagen, Robinson, \& Shneiderman, 2006; Saade, Tan, \& Nebebe, 2008), pleasure and anger (Wilfong, 2006; Venkatesh, Speier, \& Morris, 2002), and interest (Sun \& Rueda, 2012). Our understanding of CSE emotions emerged from studies of nonspecialists' experiences (Compeau \& Higgins, 1995; Beckers \& Schmidt, 2001; Barbeite \& Weiss, 2004). That is, CSE emotions have been identified in a somewhat opportunistic manner. CSE research cannot yet claim any systematic inventory of the emotions elicited during the process of learning new computing tasks. Models of emotion developed in psychology and linguistics over the past decade have converged (Scherer, 2005). "Not arbitrarily posited" (Bednarek, 2009, p. 150), these models have "gained widespread acceptance in the field of emotion research" (Kuppens, Van Mechelen, Smits, De Boeck, \& Ceulemans, 2007, p. 689), and enjoy substantial research validity (Elfenbein \& Ambady, 2002). A comprehensive inventory of nonspecialists' emotions while building a website is beyond this study. We use Appraisal analysis to gain a more comprehensive picture of emotions known to impact CSE, and identify others arising in nonspecialists across the 5-week learning period.

Multimedia authoring is taught to computing non-specialists in many disciplines (Records \& Pitt, 2003). Website-building has been an assessed project in communication courses for a decade (Johari, Bentley, Tinney, \& Chia, 2005). Contemporary students feel comfortable with web technologies, which facilitate learner-centred, project-based pedagogies (Lei \& Jao, 2007). The practice of medicine in the $21^{\text {st }}$ century is replete with computing, from integrated patient information systems reporting biometric data in hospital units, to digitised medical records, to the asymmetric control and seamless cross-platform persistence among the clinical devices practitioners use in hospital environments (Van Der Meijden, Tange, Troost, \& Hasman, 2003). Medical students receive training in the context-aware reporting devices used in clinical settings (Ward, Gordon, Field, \& Lehmann, 2001). Medicine shares technical affordances and modalities with global communication, including dynamic information displays and multimodal designs (Meinhof \& Smith, 2000). Digital communication norms have reshaped the ways doctors communicate with their public (Hawn, 2009). Web-based multimedia has become an integral part of communication with patients, and websites in particular are frequently used (Jain, 2009). Medical students are now being taught how to reach their public using web-based communication platforms (Boulos, Maramba, \& Wheeler, 2006).

KSA is ranked $26^{\text {th }}$ worldwide for the quality of its healthcare, including its IT and training (WHO, 2010). Saudi doctors accept the need for lifelong IT training (El Din, 2007). Saudi hospitals rely heavily on clinical computing for patient health information (Al-Harbi, 2011). More than 87\% of the Saudi public uses the internet to search for healthcare information (AlGhamdi \& Moussa, 2012). Thus, the Saudi government has prioritised the provision of web-based health resources (Househ, Al-Tuwaijri, \& Al-Dosari, 2010). Saudi medical students report increasing computer use for personal, professional and academic purposes, over the past decade (Mansoor, 2002; Al-Fahad, 2009; Aldebasi \& Ahmed, 2013). They have positive attitudes towards web-based communication (Al-Fahad, 2009; Alamro \& Schofield, 2012), but experience high levels of job stress (Abdulghani, Alkanhal, Mahmoud, Ponnamperuma, \& Alfaris, 2011). This study appraised the subjective responses of Saudi medical students while learning to build a website.

Medical students are less skilled at computing tasks than ubiquitous clinical computing suggests, because their knowledge reflects their area of specialisation (Paré, Sicotte, \& Jacques, 2006). Multimedia authoring is now a standard component of projects undertaken in many tertiary disciplines, including medicine (Benson, Johnson, \& Kuchinke, 2002; Boulos, Maramba, \& Wheeler, 2006). Research questions which guided this study include: what emotions and attitudes are elicited in nonspecialists while learning new computing tasks? How do positive-negative attitudinal pairs behave across the learning process? Are the emotions and beliefs they reveal the same as those which have previously been part of CSE studies?

\section{Method}

Participants were 58 women medical students at the leading English-medium-of-instruction private university in KSA. All were native-Arabic speakers who had passed TOEFL 500/667 or IELTS 5.0, indicating advanced English proficiency. Only $6=10.34 \%$ had taken a secondary-level computing course, which addressed word-processing skills only. None had taken a tertiary-level computing course, none had any programming 
experience, and none were advanced gamers. All were members of a communication course which included building a website. The 5 -week instructional period included a 1-hour training in a simple online web-page editor: http://www.wix.com, followed by $5 \times 1$-hour sessions working on websites. Instructional support came from classroom materials tailored to student needs, in-class consultations, online instructional videos, technical forums, and email advising available from http://www.wix.com. Requirements included multiple tabs with text and images, and rewarded inclusion of short sound and video files, encouraging participants to learn sound- and video-editing.

Qualitative and quantitative data were collected. Qualitative data, taken from weekly journals written by participants, was used to assess subjective attitudes over the 5 week instructional period. Quantitative data was collected via two surveys. The Before-After survey identified changes in frequencies of specific basic and advanced computing tasks over the instructional period. The Weekly Attitude Survey tracked positive and negative dimensions of $6 \mathrm{CSE}$ emotions across the instructional period.

Attitude analysis is used extensively in opinion-mining (Yang, Lin, \& Chen, 2007). Where CSE studies have combined models of emotion with states and traits, psycholinguistics treats realisations of emotions and other attitudes as part of the same system of subjective stance. Appraisal analysis, derived from systemic functional linguistics, offers the greatest delicacy in taxonomising semantic classes (Halliday \& Matthiessen, 2004). Individuals realising a personal opinion select specific words from a range of possibilities (Martin \& Rose, 2008). Neurolinguistic studies show that specific brain states are associated with the lexicogrammar that realises them (Pavlenko, 2002). Many specific emotions are experienced across human cultures, and find expression in all languages (Wurm \& Vakoch, 1996). All languages permit both direct ("I love my website") and indirect ("My friends think my website includes useful information") realisations of emotions (Martin \& White, 2005). The distinction between emotions and states found in previous CSE studies resembles that between the Affect (direct) and the two sets Judgment and Appreciation (indirect), in Appraisal Analysis.

The attitude system network is broken down into sets, categories and subcategories (Fontaine, Scherer, \& Soriano, 2013), as in Figure 1.

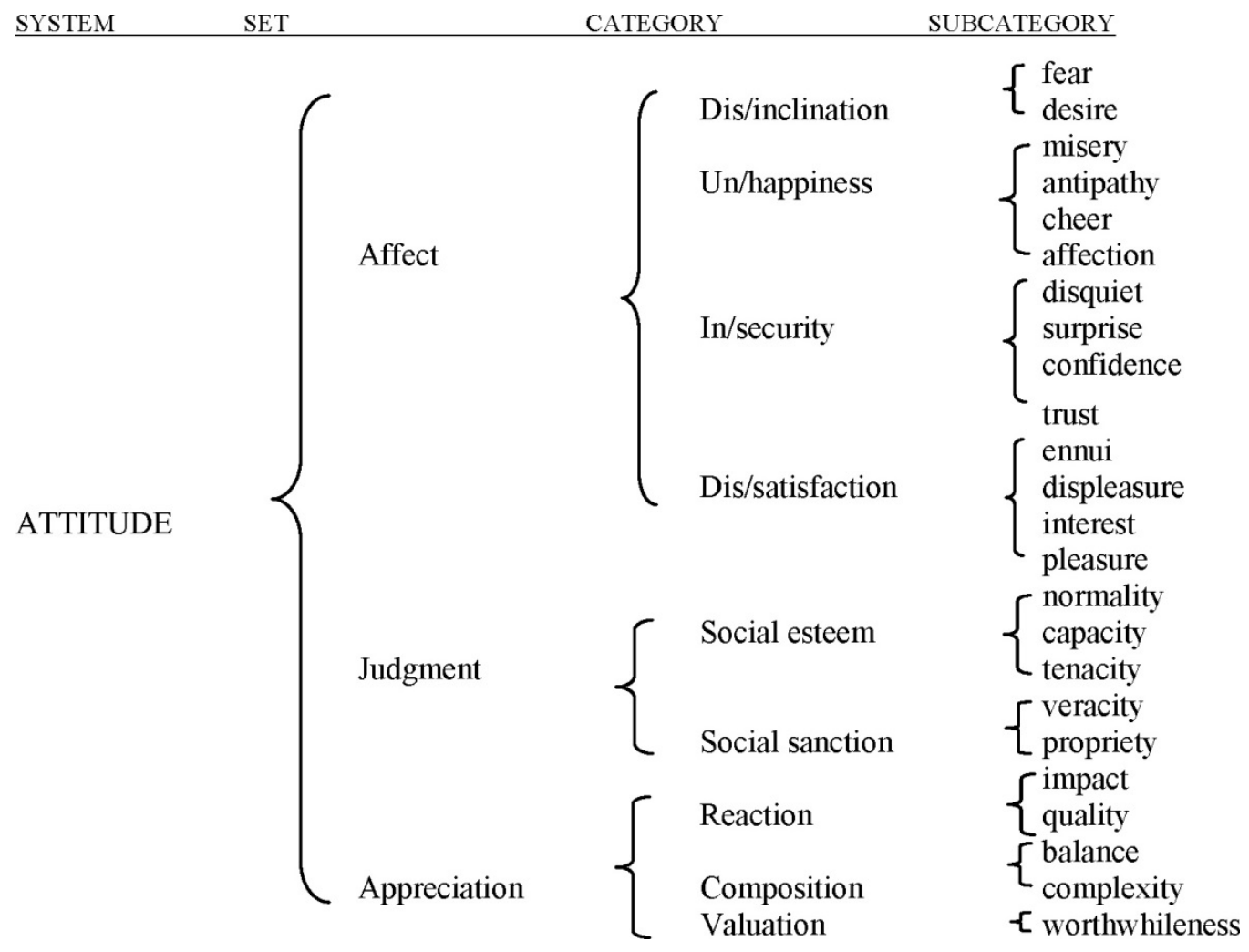

Figure 1. The attitude system 
The Affect set breaks down into the categories Dis/inclination, Un/happiness, In/security and Dis/satisfaction, further articulated into semantic subcategories. Affect underlies the other two sets, Judgment and Appreciation, which rework emotion indirectly as realisations about persons, objects, situations and events (Scherer, Schoor, \& Johnstone, 2001). Judgments of social esteem comprise subcategories for realisations of normativity, capacity and tenacity. Judgments of social sanction include realisations of veracity and propriety (Whitelaw, Garg, \& Argamon, 2005). Appreciations of reaction realise indirect subjective responses to qualities or impacts of objects and events, assess their complexity, balance, and value (Eggins, 1994).

Appraisal analysis is well-established within computational linguistics (Read \& Carroll, 2012). Concordances constructed via supervised classification tasks ground analytic approaches built up through statistical machine-learning techniques (Pang, Lee, \& Vaithyanathan, 2002). Texts containing realisations of subjective attitudes may be aggregated into a corpus, to identify patterns of subjectivity within a participant group. Machine-tagging of attitudinal lexicogrammar within electronic corpora is now routine (Balahur, Hermida, \& Montoyo, 2011). Emotional lexicogrammar is particularly easy for software to detect (Read \& Carroll, 2010). This study used Corpus Tool (CT), which includes the Appraisal system network, as well as a polarity metric (O’Donnell, 2008).

Quantitative data was collected from two surveys using a 4-point Likert scale to avoid social desirability bias and clearly differentiate between positive and negative responses (Leung, 2011). For both, 1 was "not at all", 2 was "a little", 3 was "quite a bit", and 4 was "a lot". The Before-After Survey contained 6 basic and 6 advanced computing tasks, determining which participants' engaged in prior to and after the instructional period, providing a measure of growth. The Weekly Attitude Survey used 12 items to check participants' experience of 6 specific previously-identified CSE attitudes. This survey framed items as congruent constructions ("I felt anxious about doing my website today") to elicit feedback based on personal experience (Halliday, 1985, p. xviii). It was taken weekly across the instructional period. Positive-negative pairs included: comfortable-anxious, interested-bored, enjoyment-dissatisfied, experienced-uncertain, capable-unsuccessful and fulfilled-frustrated. "Comfortable" checked emotion in Affect: In/security-confidence, where "anxious" checked negative emotion of the same kind. "Interested" checked emotion in Affect: Dis/satisfaction-interest, where "bored" checked negative emotion of the same kind. "Enjoyment" checked emotion in Affect: Dis/satisfaction-pleasure, where "dissatisfied" checked negative emotion of this kind. "Experienced" checked subjective attitudes in Judgment: Social esteem-normality where "uncertain" checked negative responses of this kind. "Capable" checked attitudes in Judgment: Social esteem-capacity where "unsuccessful" checked negative responses of this kind. "Fulfilled" checked attitudes in appreciation: valuation-worth, where "frustrated" checked negative responses of this kind. Items were pseudo-randomly ordered on the survey, to conceal their paired positive/negative structure.

Treating data from the Weekly Attitude Survey as Likert-like rather than true Likert intervals afforded a means of tracking the strength of positive/negative response over the 5-week process. While Likert-scale intervals reflect their pre-definition, not attributes of the data itself, the assumption that intervals are discrete is improbable, as participants experience variables as gradable, when responding to surveys (Goldstein \& Hersen, 1984). So "parametric statistics are robust with respect to violations of these assumptions" (Norman, 2010). Ordinal data may be treated as "Likert-type", and interpreted as continuous when questions test personality factors or attitudes, within homogeneous participant groups for whom there will not be significant skewness (Lubka \& Muthen, 2004; Ary, Jacobs, \& Sorensen, 2010).

\section{Results}

Qualitative data was collected from participants' weekly written responses. Quantitative data was taken from the Before-After and the Weekly Attitude Survey.

\subsection{Qualitative Data}

Participants' weekly journals produced a corpus of 41270 words, in 3837 sentences, across 5 weeks. This corpus contained 3562 realisations of attitude, $2443=68.58 \%$ positive and $1119=31.41 \%$ negative (see Appendix 1 ). Attitudinal density was 86.31 per thousand words. Polarity changed across the 5-week instructional period, as in Figure 2 . 


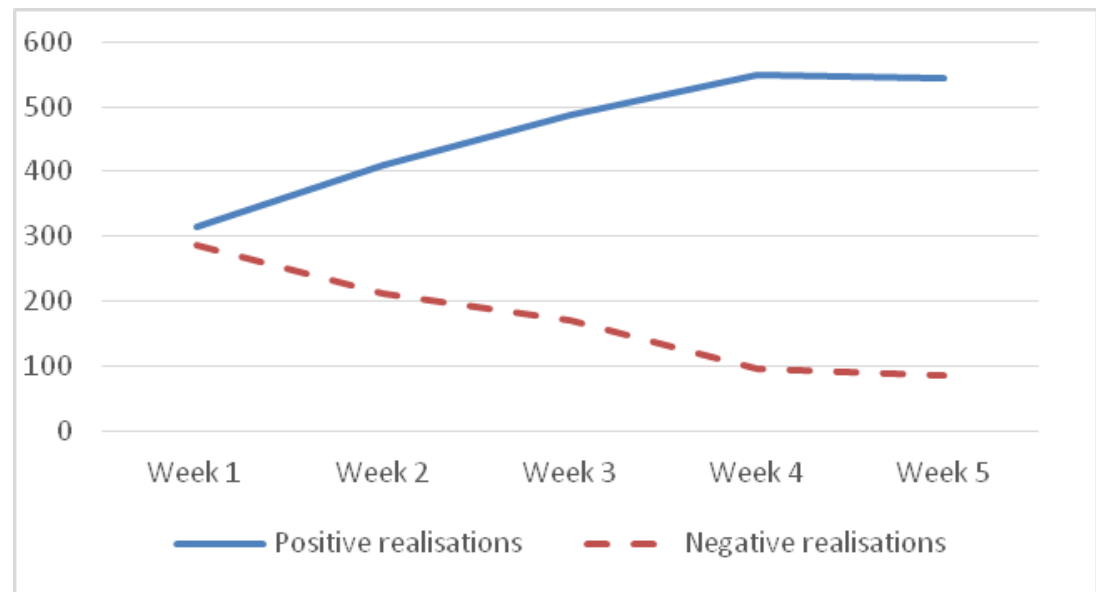

Figure 2. Corpus polarity across the instructional period

Positive and negative realisations were similar in Week 1. Positive realisations increased, where negative decreased through Week 4, with the rate of change slowing in Week 5.

Some Attitude subcategories were frequently-realised, negatively and positively, within the corpus, as in Table 1.

Table 1. Ranked most frequently-realised attitudes within the corpus overall

\begin{tabular}{lll}
\hline & $\mathrm{N}$ & \% Attitude \\
\hline capacity & 624 & 17.52 \\
interest & 519 & 14.57 \\
qualities & 509 & 14.29 \\
normality & 341 & 9.57 \\
confidence & 335 & 9.40 \\
complexity/worth & 299 & 8.39 \\
desire & 46 & 1.29 \\
impact & 28 & 0.79 \\
pleasure & 22 & 0.62 \\
\hline
\end{tabular}

As participants select their words freely, this ranking shows the attitudinal issues of greatest significance to them. Capacity was most significant, followed by interest and qualities which received very similar number of realisations. Then, normality, confidence, and complexity/worth were most frequently-realised. Desire, impact and pleasure were relatively infrequently-realised.

These frequencies appear different, when seen across the instructional period. The frequently-realised attitudes in Table 3 accounted for the majority of realisations in all weeks. The subcategory complexity was frequently-realised negatively in Weeks 1-3, and then replaced by worth, positively realised, in Weeks 3-5. These have been treated as a single variable. Capacity was realised both positively and negatively in Weeks 2-4, as was confidence in Week 5. Two subcategories were frequently-realised in the first 2 weeks; impact and pleasure. Desire was frequently-realised in Weeks 1 and 4, as in Table 2. 
Table 2. Most frequently-realised subcategories across the 5 week instructional period

\begin{tabular}{|c|c|c|c|c|c|c|c|c|c|c|c|c|c|c|c|c|c|c|c|c|}
\hline & WEEK 1 & & & & WEEK 2 & & & & WEEK 3 & & & & WEEK 4 & & & & WEEK 5 & & & \\
\hline & $N=602$ & $2315+\mathrm{vE}$ & $287-\mathrm{VE}$ & & $N=624$ & $4411+\mathrm{vE}$ & $213-v E$ & & $N=659$ & $487+v E$ & $172-\mathrm{VE}$ & & $N=647$ & $549+\mathrm{vE}$ & $98-\mathrm{VE}$ & & $N=630$ & $544+$ VE 86 & $36-V E$ & \\
\hline & $+/-$ & SUBCAT & $\mathrm{N}$ & $\%$ ATT & $+/-$ & SUBCAT & $\mathrm{N}$ & $\%$ АTT & $+/-$ & SUBCAT & $\mathrm{N}$ & \%АTT & $+/-$ & SUBCAT & $\mathrm{N}$ & $\%$ АTT & $+/-$ & SUBCAT & $\mathrm{N}$ & $\%$ ATt \\
\hline 1 & $+\mathrm{ve}$ & interest & 130 & 21.59 & $+\mathrm{ve}$ & qualities & 129 & 20.67 & $+\mathrm{ve}$ & interest & 117 & 17.75 & $+\mathrm{ve}$ & qualities & 108 & 16.69 & $+\mathrm{ve}$ & capacity & 136 & 21.59 \\
\hline 2 & $+\mathrm{ve}$ & qualities & 127 & 20.35 & $-\mathrm{ve}$ & capacity & 114 & 18.30 & $+\mathrm{ve}$ & qualities & 115 & 17.45 & $+\mathrm{ve}$ & interest & 103 & 15.92 & $+\mathrm{ve}$ & confidence & 123 & 19.52 \\
\hline 3 & $-\mathrm{ve}$ & capacity & 85 & 14.12 & $+\mathrm{ve}$ & interest & 96 & 15.38 & $-\mathrm{ve}$ & capacity & 87 & 13.20 & $+\mathrm{ve}$ & capacity & 87 & 13.45 & $+\mathrm{ve}$ & worth & 97 & 15.40 \\
\hline 4 & $-\mathrm{ve}$ & normality & 82 & 13.62 & $-\mathrm{ve}$ & normality & 72 & 11.54 & $-v e$ & normality & 51 & 7.34 & $+\mathrm{ve}$ & normality & 76 & 11.75 & $+\mathrm{ve}$ & interest & 73 & 11.59 \\
\hline 5 & $-\mathrm{ve}$ & complexity & 51 & 8.47 & $-\mathrm{ve}$ & confidence & 67 & 10.74 & $+\mathrm{ve}$ & confidence & 49 & 7.44 & $+\mathrm{ve}$ & worth & 72 & 11.13 & $+\mathrm{ve}$ & normality & 61 & 9.68 \\
\hline 6 & $-\mathrm{ve}$ & confidence & 33 & 5.48 & $-\mathrm{ve}$ & complexity & 35 & 5.61 & $+\mathrm{ve}$ & capacity & 48 & 7.28 & $+\mathrm{ve}$ & confidence & 63 & 9.74 & $-v e$ & confidence & 32 & 5.08 \\
\hline 7 & $-\mathrm{ve}$ & impact & 28 & 4.65 & $+\mathrm{ve}$ & pleasure & 22 & 3.53 & $+\mathrm{ve}$ & worth & 24 & 3.64 & $-\mathrm{ve}$ & capacity & 49 & 7.57 & $+\mathrm{ve}$ & qualities & 30 & 4.76 \\
\hline \multirow[t]{2}{*}{8} & $+\mathrm{ve}$ & desire & 16 & 2.66 & $+\mathrm{ve}$ & capacity & 18 & 2.88 & $-\mathrm{ve}$ & complexity & 20 & 3.03 & $+\mathrm{ve}$ & desire & 30 & 4.64 & -ve & interest & 28 & 4.44 \\
\hline & & & 552 & 91.69 & & & 553 & 88.62 & & & 511 & 77.54 & & & 588 & 90.88 & & & 580 & 92.06 \\
\hline
\end{tabular}

Interest and qualities behaved differently from the other frequently-realised attitudes, as in Figure 3.

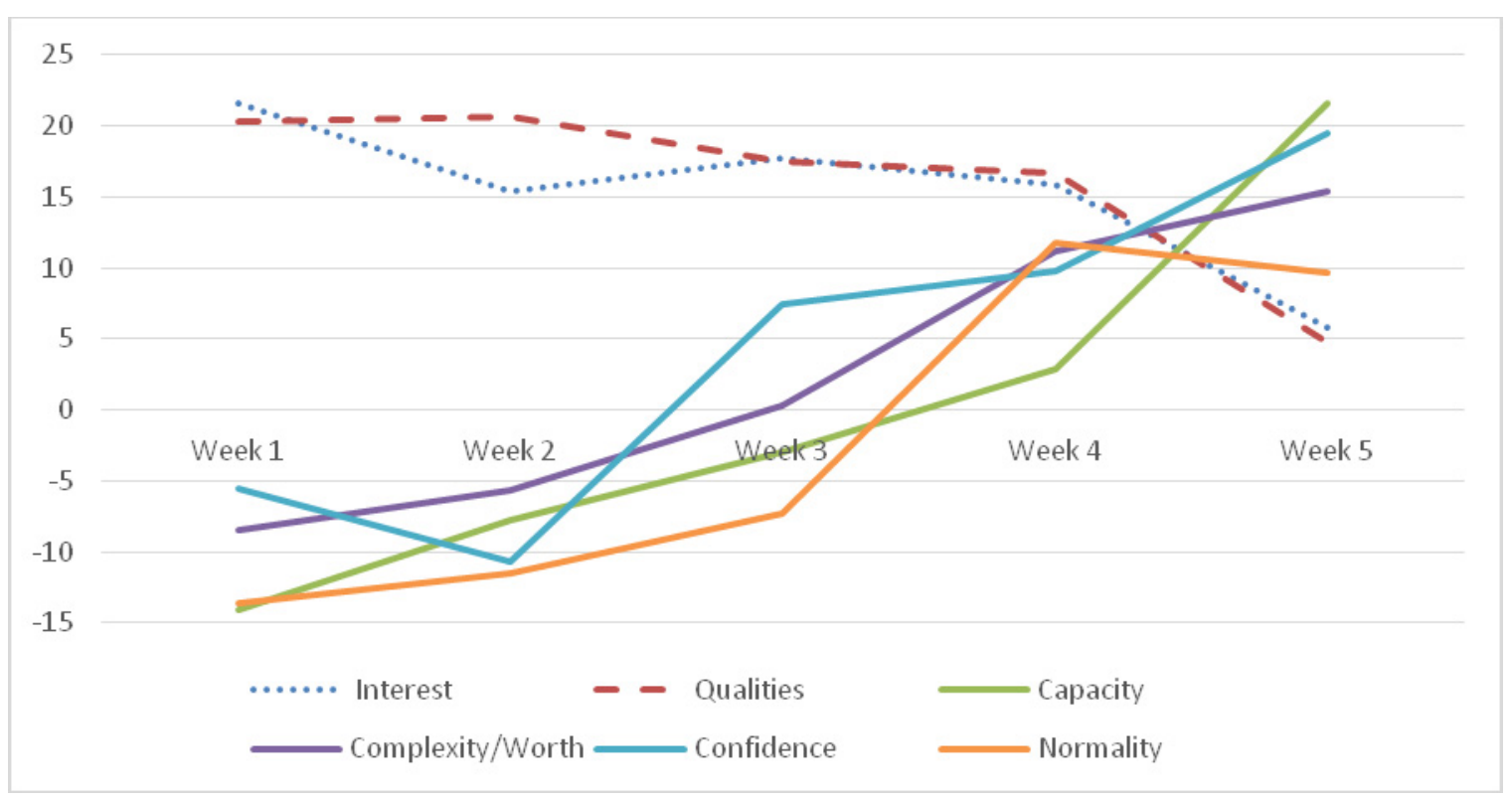

Figure 3. Frequently-realised negative/positive attitude subcategories in the Attitude data, across 5 weeks

In weeks where negative and positive realisations of the same subcategory were found, the average value was used.

The Attitude data separated emotional responses into two kinds, and separated the instructional period into 2 segments. First, interest and qualities started and remained positive in Weeks 1-4, then decreased in Week 5 . The qualities subcategory comprises realisations of the mental processes of visual perception, traditionally associated with aesthetics (Eggins, 1994; Martin \& White, 2004). But capacity, complexity/worth, confidence and normality began negative, with positive realisations increasing over Weeks 1-4, the first subjective segment. Week 5 comprised a second segment, when confidence and capacity increased sharply, worth somewhat, and normality decreased slightly.

\subsection{Quantitative Data: Weekly Attitude Survey}

The Weekly Attitude Survey elicited feedback on a 4-point Likert-scale, for 6 kinds of positive-negative pairs. For visual clarity, these are separated into 2 tables, the first showing positive-negative pairs for emotions, the second showing positive-negative pairs for other attitudes. The positive emotions comfort and enjoyment increased regularly, where their negative pairs (anxious, dissatisfied) decreased irregularly. Interest started and remained high in Weeks 1-4 after which it decreased slightly, where boredom started and remained low in Weeks 1-4, after which it increased slightly. Capacity and fulfillment increased steadily, where feeling uncertain, unsuccessful and frustrated decreased irregularly, as in Figure 4. 


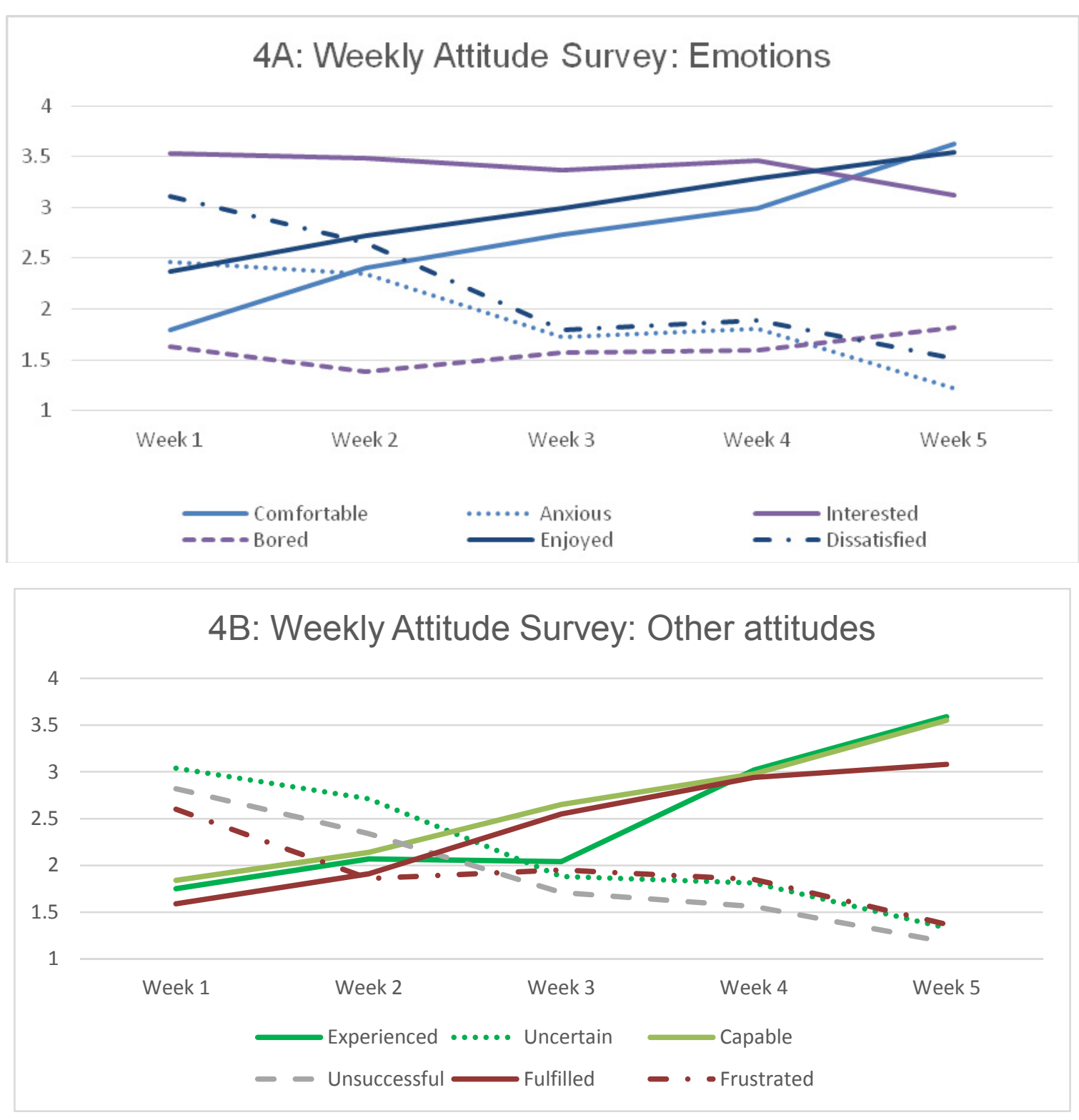

Figure 4. Weekly Attitude Survey Data*

Feeling experienced was delayed until Week 4.

\subsection{Quantitative Data: Before-After Survey}

The Before-After Survey showed changes in how often participants reported engaging in computing tasks prior to, and after building a website. There was an increase of $0.41-0.45$ of a Likert scale degree in frequency for both basic and advanced computing tasks, as in Table 3. 
Table 3. Change in reported frequency of basic and advanced computing tasks

\begin{tabular}{lllll}
\hline TASK & & BEFORE & AFTER & $\Delta$ \\
\hline basic & used social media websites & 3.43 & 3.57 & 0.14 \\
& downloaded soundfiles & 3.17 & 3.43 & 0.26 \\
& downloaded tv shows or movies & 3.16 & 3.74 & 0.58 \\
& played games on my phone & 2.60 & 3.16 & 0.56 \\
& played games on my laptop/desktop & 2.22 & 2.86 & 0.64 \\
& edited photos & 1.50 & 2.01 & 0.51 \\
& & avg: 2.68 & avg: 3.13 & avg $\Delta: 0.45$ \\
advanced & & & \\
& & & & \\
& edited sound files & 1.14 & 2.68 & 1.54 \\
& edited tv/movie files & 1.34 & 1.79 & 0.45 \\
& played games on a console like Wii, Playstation & 2.16 & 2.33 & 0.17 \\
& played MMORPGs on my laptop/desktop & 1.29 & 1.29 & 0.00 \\
& played MMORPGs on a console like Wii, Playstation & 1.21 & 1.21 & 0.00 \\
& created an avatar & 2.26 & 2.56 & 0.30 \\
& & avg: 1.57 & avg: 1.98 & avg $\Delta: 0.41$ \\
\hline
\end{tabular}

For basic computing tasks, participants' reported use of social media began and remained high. Gains were high for downloading tv/movie files, probably due to the desire to include sound and video clips on their webpages. For advanced tasks, editing photos rose more than average, probably due to the requirement to include images on webpages. Editing sound files showed the greatest increase of all tasks. Editing tv/movie files showed greater than average increase. In most cases, this meant cutting a longer file down to a 2 minute segment, or cutting and splicing segments. In all, $17=29.31 \%$ reported learning to use iMovie Editor. Increases in gaming have no obvious connection to website-building tasks. Anecdotal evidence indicated that gaming increases at the end of the instructional period, coinciding with the end of semester and the pressure of exams and projects coming due, mainly reflected participants' normal habits for dealing with stress, and that this pattern had been part of their responses to the pressure of deadlines prior to the time period of this study. While it is possible that there was a greater increase than would have occurred without the increased awareness of and engagement with the website-building experience, this could not be determined within the framework of this study.

\section{Discussion}

Qualitative and quantitative data show that building a website was an increasingly positive experience. In the Attitude data, negative and positive realisations began nearly equal, with positive realisations about 6 times greater in Week 5. The Weekly Attitude Survey data showed increasing positive and decreasing negative emotions. This is consonant with CSE studies understanding CSE emotions as a positive-negative correlation. But most positive-negative pairs did not behave correlatively across the instructional period. Two attitudes, interest and qualities, behaved correlatively, showing little change across the instructional period. For example:

The design process of making your own website is very enjoyable. I am constantly trying out exciting new options [+Ap: R-quality] and changing to a more inspiring [+Ap: R-quality] design. I changed the background of my website to more lighter colors that suits my topic [+Ap: R-quality].

Here, the visual process evokes positive feelings of enjoyment which are reworked as qualities attributed to design features ("inspiring design", "colors which suit"). The similar frequencies of interest and qualities across the instructional period suggest the visual elements of website building design generated positive interest. This is supported by finding positive/negative realisations of Affect: Dis/satisfaction-interest with Appreciations: Reaction-quality in $631=16.4 \%$ of sentences:

I found interesting [+Af: Dis/sat-int] YouTube videos about my topic and added one of them to make my website more attractive [+Ap: Reaction-qual]. 
My experience with editing pictures this week was extremely remarkable [+Ap: Reaction-qual] and I feel more excited[+Af: Dis/sat-int] to finalize my website in creative manner [+Ap: Reaction-qual] and publish it to the world.

I added a few pictures that were strongly on topic [+Ap: Reaction-qual] to my website since it looked pretty dull [-Af: Dis/sat-int] and boring [-Af: Dis/sat-int].

But five emotions did not covary. Data from the Weekly Attitude Survey showed enjoyment and comfort increasing steadily across the instructional period. Comfort, the positive pair to anxiety, has not been included in previous CSE studies. For comfort and anxiety, enjoyment and dissatisfaction, capable and unsuccessful, fulfilled and frustrated, the positive emotion increased steadily but the negative emotions decreased irregularly and sometimes increased. This is most evident in the experienced-uncertain pair, where rates of increase and decrease are quite dissimilar. Patterns of decrease of negative emotions probably reflect participants' engagement with new tasks early on, and in Weeks 4-5 the approaching deadline. Overall, positive and negative dimensions of the same emotion did not covary during the learning process, and negative emotions were more variable.

Appraisal analysis showed some CSE emotions as sporadic, being frequently-realised only at certain points in the learning process. This probably reflected the initial encounter with new tasks, as for impact in Week 1 ("the templates are amazing [+Ap: R-imp]"). As impacts realise the impression made by items outside the self on the self, we would expect them to decrease with familiarity. The disappearance of specific emotions during the learning process may reflect success in learning new tasks, as for pleasure in Week 2:

While working on my website this week, I was quite pleased [+Af: Dis/sat-ple]. The pictures, panels and quotes were properly arranged and looked very neat. Some things were easier than I expected. Initially, I thought attaching video clips to the website would be difficult, but it was easy to do. In the end I was very happy [+Af: Dis/sat-ple] with how the website looked.

But the later infrequent realisation of pleasure cannot be taken to indicate displeasure, due to the sixfold increase in positive realisations over the 5 weeks, suggesting other attitudes took the place of pleasure. Frequent realisation of desire seemed to mark some of these stages in the learning process. Frequent realisations in Week 1 marked the initial encounter with the project ("I started to have many ideas regarding how do I want [+Af: Dis/incl-des] my final webpage to look like"), and their end-of-project aspirations in Week 4 ("The experience was one of a kind and it is interesting to think what I could do if I wanted [+Af: Dis/incl-des] to create another website").

The most frequently-realised attitude overall, capacity (for example "can", "able to", "have the ability to", "capable of"), realised negatively in Week 1, positively and negatively in Weeks 2-4, and positively in Week 5, comprised about one-sixth of all attitudinal realisations, indicating its pre-eminent significance to participants. This is consonant with previous CSE studies finding that positive experiences shape self-beliefs about ability. The overall sense of increasing capacity is evident in realisations across the instructional period:

Week 1: I figured out how to [+Ap: Reaction-cap] add pictures without losing my work. But I wasn't able to [-Ap: Reaction-cap] add a slide show to the home page.

Week 2: I can [+Ap: Reaction-cap] undo things easy now, not like at the beginning I did not know how to [-Ap: Reaction-cap] undo things, so I was doing the whole thing all over again.

Week 3: I'm getting the hang of [+Ap: Reaction-cap] this quicker than I thought I would. I had to ask a friend of mine for help once or twice, but now I'm relying more on figuring my way [+Ap: Reaction-cap] through this by myself, which is really fun.

Week 4: I am no longer frustrated working on the website, and as more time passes by, I am able to [+Ap: Reaction-cap] edit pictures, add or delete texts, change background colors and settings, comfortably. I found a way to [+Ap: Reaction-cap] crop the video that I have to 1 minute by using YouTube editor.

Week 5: I found creative ideas that I never thought I will be able to [+Ap: Reaction-cap] come up with. This project helped me to think outside of the box indeed! The advantages earned by this project are that I am able to [+Ap: Reaction-cap] create my own website in the near future.

In CSE studies, "perceived ease of use" is understood to motivate learning new tasks and to shape expectations for learning outcomes. In psycholinguistics, the modality of possibility signifies active potentials within the person, which have been customarily instantiated in action, and on this basis frame future potentials (Panther \& Thornburg, 1999). That is, "Now I know how to [+Ap: Reaction-cap] use iMovie, I can [+Ap: Reaction-cap] cut 
the video to 2 minutes" assumes past experience underwriting the claim of ability, and projects a future action the writer intends to engage in (Stack, 2012). This grammeme assumes, but does not express a past time during which the ability was learned (Kostusyak, 2013). The person realising the modality of ability positively must view the learning process as past, and not relevant to their current state of being. Negative realisations frame the potential, from the stage before it is acquired. Both positive and negative realisations of capacity increasing strongly in Weeks 1 and 2, indicating a view of self as able and not-able while actively pursuing the able state. By Week 3, positive realisations increase as negative realisations decrease, suggesting realisations of capacity delineate two phases in the learning process: an active, ambivalent phase, and an able, intentional phase. This may also be visible in the stronger decrease in "unsuccessful" than increase for the positive "capable" in Weeks 1-3 of the Weekly Emotion Survey data. If generalised to learning a variety of computing tasks, the required length of time would vary, reflecting learners and tasks.

Confidence and normality each comprised about $10 \%$ of attitudes realised, moving irregularly from frequent negative to increasing positive attitudes, with exceptional weeks. The Week 2 decrease probably reflected the challenge of learning new tasks:

Week 2: Here I am at the second week of constructing my website, and I'm afraid it's not as easy [-Af: $\mathrm{In} / \mathrm{Sec}$-conf] as I thought.

Week 2: Because this week I faced certain challenges, I don't believe [-Af: In/Sec-conf] my webpage progressed very much.

Week 2: I think the second week experience was quite harder [-Af: In/Sec-conf] than the first week.

Confidence increased slightly Weeks 3-4, and strongly in Week 5:

Week 3: "I have managed to organize my menu bar in a good way, I think [+Af: In/Sec-conf]."

Week 4: I believe [+Af: In/Sec-conf] the more time I will spend on building my website, the more I will find new and different ways to edit and design.

Week 5: Working on the website at this stage, I am almost sure [+Af: In/Sec-conf] I know how to do everything and it is easy to do, unlike the first time I start on it.

CSE studies understand self-beliefs as a judgment based on prior experience, grounding individuals' views of their ability to perform specific actions and gain desired outcomes in future. Capacity and confidence frame the same ground, but focused on the self. Confidence is an emotion. Directly realised, it bears a congruent relation to inner experience, making it a strong indicator of learner self-concept. Capacity is realised indirectly, using modality ("can"), grammatical metaphor ("ability", "figuring my way"), and being lexicalised across many elements of a sentence ("got the hang of"), which place the experience at a greater distance from the self (Bloor $\&$ Bloor, 2004). While the curves in Figure 5 for capacity and confidence were created from an average of positive and negative values, positive values for confidence rise slower and later than those for capacity. This suggests a third phase, after a few weeks of capable practice, which is when the learner places the experience of the task close to the self, realising it congruently.

Realisations of normality may be used to delineate when learners become habituated to the new computing tasks. Judgments of normality construe how special or ordinary something is to us:

Week 1: It was really special [+J: Social esteem-norm] seeing how many template designs there are to choose from.

Week 2: "Making a website is a whole different [ $+\mathrm{J}$ : Social esteem-norm] ballgame. I have never done this before".

Week 3: At first it seemed impossible, for person like me, who is technologically challenged, since I have never done something like this before but, with time and some effort, it became manageable, even special $[+\mathrm{J}$ : Social esteem-norm].

Week 4: In my opinion, the overall experience is great. It is very beneficial and different [+J: Social esteem-norm] at the same time.

Week 5: The website experience was an exceptional [ $+\mathrm{J}$ : Social esteem-norm] one for me. This project was completely a new level $[+\mathrm{J}$ : Social esteem-norm] of challenges and advancements.

In the Attitude data, positive realisations of normality grew slowly in Weeks 1-3, peaked in Week 4, then decreased slightly. Realisations of normality apparently adjudicate how usual/unusual something is. But to make this evaluation, the writer must project her personal experience onto her environment, using it as a norm in 
assessing the new experience. Thus, these realisations actually show the writer's view of how well the new task integrates with her past experiences. So, the Week 1 comment is best interpreted as realising the writer's inexperience with website templates. The somewhat positive lexis of Week 2 ("different"), increasingly positive lexis of Weeks 3-4 ("special", "beneficial and different") and very positive lexis of Week 5 ("exceptional", "new level") are best interpreted as participants viewing website building as a positive but unusual task. In this case, polarity tends to reflect how well-integrated the new experience is. The learning process would appear as a curve which increased strongly, with integration of a computing task into nonspecialists' computing experiences shown by the curve for realisations of normality then decreasing almost as much. The slight decrease in Week 5 is not enough to show normalisation, and 5 weeks is unlikely to be enough time to normalise a task.

Finally, complexity and worth, frequently-realised in the Attitude data, have not been part of previous CSE studies.

Week 1: When I first heard about this assignment, I definitely felt overwhelmed. For me the use of technology on its own is quite difficult [-Ap: Comp-comp].

Week 2: I used my own camera and I tried to edit using my brother's program. But I found editing extremely complicated [-Ap: Comp-comp].

Week 3: The technical difficulties [-Ap: Comp-comp] were adding videos, sound, and how to put the menu. But I have a clear idea of what the website needs. It gives me confidence and some very valuable [+Ap: Val-wor] skills.

Week 4: Knowing that there is nothing hard when you try doing it, is the most important [+Ap: Val-wor] thing I have learned by generating my own website.

Week 5: Actually, after I published my website today and saw the amazing achievement [+Ap: Val-wor] I did, I felt that it is worth [+Ap: Val-wor] it to spend time to achieve [+Ap: Val-wor] such a piece of work.

The change from negative complexity to positive worth appears to reflect a sense of achievement in learning new tasks, comparable to the growth of capacity and confidence.

The Weekly Emotion Survey and the Attitude data both showed that participants experienced the final week as a distinct emotional segment. Most attitudes showed a change in Week 5, with decreasing positive or reversing polarity probably reflecting the pressure of the deadline. At the same time, the Before-After Survey confirmed that participants had increased their computing activity outside of class, at the end of the instructional period. While increased gaming may reflect the stress of the deadline, gains in editing sound and video reflect abilities gained in building a website.

This study has explored nonspecialists' attitudes towards learning new computing tasks. Quantitative data shows an increase in engagement with basic and advanced computing tasks as a result of building the website, with notable gains in two advanced tasks, editing sound- and video-files. However, there are limitations. The number of participants is small, making the results provisional in character. The high academic self-efficacy of medical students makes them a reliable initial group to study, but further studies with other groups are required to generalise these findings to other populations.

This study's four main conclusions reflect its treatment of learning as a process, and the collecting of comprehensive attitudinal data across a 5-week period. First, attitudes are changeable, some being significant early in the learning process, and others later on. Some occur sporadically, for example impact and pleasure. Second, this study highlights the importance of interpreting frequency and polarity separately, with incidence a better guide to an attitude's importance to participants. That positive and negative dimensions of many emotions did not covary, and negative emotions were more variable, reveal CSE emotions as much more complex than the current understanding, and invites further study. The strong, correlative data for interest and perceptual qualities suggest that multimedia authoring is a useful vehicle for teaching nonspecialists. However, as many computing tasks are not visually stimulating, this is not widely applicable.

Third, the attitude data suggests learning occurs in stages, starting with an active but subjectively ambivalent sense of capability. A second phase is positively able and intentional, with learners instantiating cognitive potentials to achieve objectives. A third phase is reflected in realisations of confidence, with learners placing the experience close to the self, in effect "owning it". Deadlines may create their own attitudinal microclimate, causing changes in polarity and eliciting unique emotions. As this issue is relevant to nonspecialist learning in the university and the workplace, studies of attitude approaching and following deadlines are needed to indicate how they interact with CSE. Realisations of normality offer a means of checking how accustomed learners have become to a specific task, with strongly decreasing frequencies indicating normalisation. 
Finally, this study has shown the value of using contemporary psycholinguistic methods to study CSE. Some CSE emotions were not frequently-realised, including anxiety and anger and frustration, when participants feely chose what attitudes to realise. While this may reflect cultural norms, or the specific participant group selected, it indicates the potential for Appraisal subcategories to refine current understanding, for example in using capacity, confidence and normality to articulate "perceived ease of use". While this paper cannot theorise the integration of Appraisal analysis with the states-and-traits models of emotion used in most CSE studies, it shows the value of casting the net wider, and using a finer mesh, when studying CSE emotions.

\section{References}

Abdulghani, H. M., AlKanhal, A. A., Mahmoud, E. S., Ponnamperuma, G. G., \& Alfaris, E. A. (2011). Stress and its effects on medical students: A cross-sectional study at a college of medicine in Saudi Arabia. Journal of health, population, and nutrition, 29(5), 516. http://dx.doi.org/10.3329/jhpn.v29i5.8906

Alamro, A. S., \& Schofield, S. (2012). Supporting traditional PBL with online discussion forums: A study from $\begin{array}{lllll}\text { Qassim Medical } \quad \text { School. } & \text { Medical }\end{array}$ http://dx.doi.org/10.3109/0142159X.2012.656751

Aldebasi, Y. H., \& Ahmed, M. I. (2013). Computer and Internet Utilization among the Medical Students in Qassim University, Saudi Arabia. Journal of clinical and diagnostic research, 7(6), 1105-1108. http://dx.doi.org/10.7860/jcdr/2013/5891.3092

Al-Fahad, F. N. (2009). Students' Attitudes and Perceptions towards the Effectiveness of Mobile Learning in King Saud University, Saudi Arabia (Vol. 8, No. 2). Retrieved from http://www.files.eric.ed.gov/fulltext/ED505940.pdf

Alghamdi, K. M., \& Moussa, N. A. (2012). Internet use by the public to search for health-related information. $\begin{array}{llll}\text { International journal of medical informatics, } & 81(6), & 363-373 .\end{array}$ http://dx.doi.org/10.1016/j.jimedinf.2011.12.004

Al-Harbi, A. (2011). Healthcare providers' perceptions towards health information applications at King Abdul-Aziz Medical City, Saudi Arabia. International Journal of Advanced Computer Science Applications, 2(10), 10-13. http://dx.doi.org/10.14569/IJACSA.2011.021003

Artino, A., La Rochelle, J., \& Durning, S. (2010). Second-year medical students' motivational beliefs, emotions $\begin{array}{llll}\text { and } & \text { achievement. Medical } & \text { Education, } & \text { 44(12), }\end{array}$ http://dx.doi.org/10.1111/j.1365-2923.2010.03712.x

Balahur, A., Hermida, J. M., \& Montoyo, A. (2011). Detecting implicit expressions of sentiment in text based on commonsense knowledge. In Proceedings of the 2nd Workshop on Computational Approaches to Subjectivity and Sentiment Analysis (pp. 53-60). Association for Computational Linguistics, Massachussetts.

Bandura, A. (1986). Social foundations of thought and action: A social cognitive theory. Englewood Cliffs, NJ: Prentice-Hall.

Bandura, A. (1997). Self-efficacy: The exercise of control. New York, Freeman.

Bandura, A. (2006). Toward a psychology of human agency. Perspectives on Psychological Science, 1(2), 164-180. http://dx.doi.org/10.1111/j.1745-6916.2006.00011.x

Bandura, A., Caprara, G., Barbaranelli, C., Gerbino, M., \& Pastorelli, C. (2003). Role of affective self-regulatory efficacy in diverse spheres of psychosocial functioning. Child Development, 74(3), 769-782. http://dx.doi.org/10.1111/1467-8624.00567

Barbeite, F. G., \& Weiss, E. M. (2004). Computer self-efficacy and anxiety scales for an Internet sample: Testing measurement equivalence of existing measures and development of new scales. Computers in Human Behavior, 20(1), 1-15. http://dx.doi.org/10.1016/S0747-5632(03)00049-9

Beckers, J., \& Schmidt, H. (2001). The structure of computer anxiety: A six factor model. Computers in Human Behavior, 17(1), 35-49. http://dx.doi.org/10.1016/S0747-5632(00)00036-4

Benson, A., Johnson, S., \& Kuchinke, K. (2002). The use of technology in the digital workplace: A framework for human resource development. Advances in Developing Human Resources, 4(4), 392-404. http://dx.doi.org/10.1177/152342202237518 
Bessière, K., Newhagen, J., Robinson, J., \& Shneiderman, B. (2006). A model for computer frustration: The role of instrumental and dispositional factors on incident, session, and post-session frustration and mood. Computers in Human Behavior, 22(6), 941-961. http://dx.doi.org/10.1016/j.chb.2004.03.015

Bhattacherjee, A. (2001). Understanding Information Systems Continuance: An Expectation Confirmation Model. MIS Quarterly, 25(3), 351-370. http://dx.doi.org/10.2307/3250921

Bloor, T., \& Bloor, M. (2004). The Functional Analysis of English. Hodder Education, Great Britain.

Bong, M., \& Skaalvik, E. M. (2003). Academic self-concept and self-efficacy: How different are they really? Educational Psychology Review, 15(1), 1-40. http://dx.doi.org/10.1023/A:1021302408382

Boulos, M. N., Maramba, I., \& Wheeler, S. (2006). Wikis, blogs and podcasts: A new generation of Web-based tools for virtual collaborative clinical practice and education. BMC Medical Education, 6(1), 41. http://dx.doi.org/10.1186/1472-6920-6-41

Caprara, G., Vecchione, M. J., Alessandri, G., \& Barbaranelli, C. (2011). The contribution of personality traits and self-efficacy beliefs to academic achievement: A longitudinal study. British Journal of Educational Psychology, 81(1), 78-96. http://dx.doi.org/10.1348/2044-8279.002004

Chen, G., Gully, S., Stanley, M., Whiteman, J.-A., \& Robert, N. (2000). Examination of relationships among trait-like individual differences, and learning performance. Journal of Applied Psychology, 85(6), 835-847. http://dx.doi.org/10.1037/0021-9010.85.6.835

Coffin, R., \& Mackintyre, P. (2000). Cognitive, motivation and affective processes associated with computer-related performance: A path analysis. Computers in Human Behavior, 16(2), 199-222.

Compeau, D., \& Higgins, C. (1995). Computer self-efficacy: Development of a measure and initial test. MIS Quarterly, 20(4), 189-211. http://dx.doi.org/10.1016/S0747-5632(99)00054-0

Compeau, D. R., Higgins, C. A., \& Huff, S. (1999). Social cognitive theory and individual reactions to computing technology: A longitudinal study. MIS Quarterly, 23, 145. http://dx.doi.org/10.2307/249749

El Din, M. (2007). Physicians' use of and attitudes toward electronic medical record system implemented at a teaching hospital in Saudi Arabia. Journal of the Egypt Public Health Association, 82(5), 347-364.

Fischer, G., \& Konomi, S. (2005). Innovative media in support of distributed intelligence and lifelong learning. In Proceedings of the 3rd IEEE International Workshop in Wireless and Mobile Learning (pp. 3-10). Los Alamitos, CA, IEEE Computer Society. http://dx.doi.org/10.1109/wmte.2005.35

Garland, K. J., \& Noyes, J. M. (2008). Computer attitude scales: How relevant today. Computers in Human Behavior, 24(2), 563-575. http://dx.doi.org/10.1016/j.chb.2007.02.005

Kremer, M., Brannen, C., \& Glennerster, R. (2013). The challenge of education and learning in the developing world. Science, 340(6130), 297-300. http://dx.doi.org/10.1126/science.1235350

Hasan, B. (2003). The influence of specific computer experiences on computer self-efficacy beliefs. Computers in Human Behaviour, 19(4), 443-450. http://dx.doi.org/10.1016/S0747-5632(02)00079-1

Hawn, C. (2009). Take two aspirin and tweet me in the morning: How Twitter, Facebook, and other social media are reshaping health care. Health Affairs, 28(2), 361-368. http://dx.doi.org/10.1377/hlthaff.28.2.361

Househ, M., Al-Tuwaijri, M., \& Al-Dosari, B. (2010). Establishing an Electronic Health Center of Research Excellence (E-CoRE) within the Kingdom of Saudi Arabia. Journal of Health Informatics in Developing Countries, 4(1), 42-46. Retrieved from http://www.jhidc.org/index.php/jhidc/issue/view/9

Jain, S. H. (2009). Practicing medicine in the age of Facebook. New England Journal of Medicine, 361(7), 649-651. http://dx.doi.org/10.1056/NEJMp0901277

Johari, A., Bentley, J. P., Tinney, M. V., \& Chia, B. H. (2005). Intercultural Internet-based learning: Know your audience and what it values. Educational Technology Research and Development, 53(2), 117-127. http://dx.doi.org/10.1007/BF02504870

Kostusyak, N. (2013). Category of syntactic modality and its grammeme implications. Linguistic Studies, 26(1), 99-103.

Kousta, S. T., Vinson, D. P., \& Vigliocco, G. (2009). Emotion words, regardless of polarity, have a processing $\begin{array}{lllll}\text { advantage over neutral } & \text { words. }\end{array}$ http://dx.doi.org/10.1016/j.cognition.2009.06.007 
Lei, J., \& Zhao, Y. (2007). Technology uses and student achievement: A longitudinal study. Computers \& Education, 49(2), 284-296. http://dx.doi.org/10.1016/j.compedu.2005.06.013

Paré, G., Sicotte, C., \& Jacques, H. (2006). The effects of creating psychological ownership on physicians' acceptance of clinical information systems. Journal of the American Medical Informatics Association, 13(2), 197-205. http://dx.doi.org/10.1197/jamia.M1930

Van Der Meijden, M. J., Tange, H. J., Troost, J., \& Hasman, A. (2003). Determinants of success of inpatient clinical information systems: A literature review. Journal of the American Medical Informatics Association, 10(3), 235-243. http://dx.doi.org/10.1197/jamia.M1094

Mansoor, I. (2002). Computer skills among medical learners: A survey at King Abdul Aziz University, Jeddah. Journal of Ayub Medical College, 14(3), 13-15.

Pekrun, R., Goetz, T., Titz, W., \& Perry, R. (2010). Academic emotions in students' self-regulated learning and achievement: A program of qualitative and quantitative research. Educational Psychologist, 37(2), 91-105. http://dx.doi.org/10.1207/S15326985EP3702_4

Read, J., \& Carroll, J. (2012). Annotating expressions of appraisal in English. Language resources and evaluation, 46(3), 421-447. http://dx.doi.org/10.1007/s10579-010-9135-7

Records, H. A., \& Pitt, R. E. (2003). Teaching digital multimedia as a component of business education. Journal of Information Systems Education, 14(1), 31-40. Retrieved from http://www.jise.org/Volume14/14-1/Pdf/14(1)-031.pdf

Saade, G., \& Kira, D. (2009). Computer Anxiety in E-Learning: The Effect of Computer Self-Efficacy. Journal of Information Technology Education, 8, 177-191. Retrieved from http://www.article_111397.pdf

Saade, R. G., Tan, W., \& Nebebe, F. (2008). Impact of motivation on intentions in online learning: Canada vs China. Setting Knowledge Free: The Journal of Issues in Informing Science and Information Technology, 5, 137-149. Retrieved from http://www.books.google.com.sa/books?hl=en\&lr=\&id=lglMGml6fggC\&oi= fnd\&pg $=$ PA137\&dq $=$ Impact + of + motivation + on + intentions + in + online + learning $:+$ Canada $+v s+$ China\&ots $=$ cFAZX0KKtw\&sig=MXtwdyTmfsqKQb64bccODBmwnb8\&redir_esc $=y \# v=$ onepage \& $\mathrm{q}=$ Impact $\% 20 \mathrm{of} \% 2$ 0motivation\%20on\%20intentions\%20in\%20online\%20learning\%3 $\%$ 20Canada $\% 20 v$ s $\% 20$ China\& $\mathrm{f}=$ false

Scherer, K. R. (2005). What are emotions? And how can they be measured? Social science information, 44(4), 695-729. http://dx.doi.org/10.1177/0539018405058216

Schuck, D., \& Ertmer, P. (2000). Self-regulation and academic learning: Self-efficacy enhancing interventions. In P. Boekarts, M. Pintrich, \& M. Zeider (Eds.), Handbook of self-regulation (pp. 631-649). San Diego, California: Academic Press.

Sun, J., \& Rueda, R. (2012). Situational interest, computer self-efficacy and self-regulation: Their impact on student engagement in distance education. British Journal of Educational Technology, 43(2), 191-204.

Torkzadeh, G., Pflughoeft, K., \& Hall, L. (1999). Computer self-efficacy, training effectiveness and user attitudes: An empirical study. Behaviour and Information Technolog, 18(4), 299-309.

Torkzadeh, G., \& Van Dyke, T. (2002). Effects of training on internet self-efficacy and computer user attitudes. Computers in Human Behavior, 18(5), 479-494. http://dx.doi.org/10.1016/S0747-5632(02)00010-9

Veletsianos, G. (2010). Contextually relevant pedagogical agents: Visual appearance, stereotypes and first impressions and their impact on learning. Computers \& Education, 55, 576-585. http://dx.doi.org/10.1016/j.compedu.2010.02.019

Venkatesh, V. (2000). Determinants of Perceived Ease of Use: Integrating Control, Intrinsic Motivation and Emotion into the Technology Acceptance Model. Information System Research, 11(4), 342-365. http://dx.doi.org/10.1287/isre.11.4.342.11872

Venkatesh, V., Speier, C., \& Morris, M. (2002). User acceptance enablers in individual decision making about technology: Toward an integrated model. Decision Sciences, 33(2), 297-316. http://dx.doi.org/10.1111/j.1540-5915.2002.tb01646.x

Wang, E., Myers, M. D., \& Sundaram, D. (2012). Digital natives and digital immigrants: Towards a model of digital fluency. ECIS Proceedings, 2012, 39. Retrieved from http://www.aisel.aismet.org/ecis2012/39

Ward, J. P., Gordon, J., Field, M. J., \& Lehmann, H. P. (2001). Communication and information technology in medical education. Lancet, 357(9258), 792-796. http://dx.doi.org/10.1016/S0140-6736(00)04173-8 
Whitelaw, C., Garg, N., \& Argamon, S. (2005). Using appraisal groups for sentiment analysis. In Proceedings of the 14th ACM international conference on Information and knowledge management (pp. 625-631). ACM. http://dx.doi.org/10.1145/1099554.1099714

Wilfong, J. (2006). Computer anxiety and anger: The impact of computer use, computer experience, and self-efficacy beliefs. Computers in Human Behavior, 22(6), 1001-1011. http://dx.doi.org/10.1016/j.chb.2004.03.020

World Health Organisation. (2010). World health statistics, 2010. France, Word Health Organization.

\section{Appendix}

\section{Attitude Data}

\begin{tabular}{|c|c|c|c|c|c|c|}
\hline \multirow[b]{3}{*}{ AFFECT } & \multicolumn{6}{|c|}{ ATTITUDE $(\mathrm{N}=3562)$} \\
\hline & \multicolumn{3}{|c|}{ positive $(n=2443,68.58 \%)$} & \multicolumn{3}{|c|}{ negative $(n=1119,13.41 \%)$} \\
\hline & $\mathbf{N}$ & $\%+v e$ & $\%$ ATT & $\mathbf{N}$ & $\%$-ve & $\%$ ATT \\
\hline \multicolumn{7}{|c|}{ dis/inclination } \\
\hline fear & 27 & 1.11 & 0.76 & 19 & 1.70 & 0.53 \\
\hline desire & 46 & 1.88 & 1.29 & 25 & 2.23 & 0.70 \\
\hline \multicolumn{7}{|c|}{ un/happiness } \\
\hline misery & 21 & 0.86 & 0.59 & 16 & 1.43 & 0.45 \\
\hline antipathy & 28 & 1.15 & 0.78 & 13 & 1.16 & 0.36 \\
\hline cheer & 35 & 1.43 & 0.98 & 22 & 1.97 & 0.62 \\
\hline affection & 43 & 1.76 & 1.21 & 7 & 0.63 & 0.20 \\
\hline \multicolumn{7}{|l|}{ in/security } \\
\hline disquiet & 33 & 1.35 & 0.93 & 21 & 1.88 & 0.59 \\
\hline surprise & 41 & 1.68 & 1.15 & 24 & 2.14 & 0.67 \\
\hline confidence & 132 & 5.40 & 3.71 & 100 & 8.94 & 2.81 \\
\hline trust & 28 & 1.15 & 0.79 & 14 & 1.25 & 0.39 \\
\hline \multicolumn{7}{|c|}{ dis/satisfaction } \\
\hline ennui & 40 & 1.64 & 1.12 & 23 & 2.06 & 0.65 \\
\hline displeasure & 42 & 1.72 & 1.18 & 18 & 1.61 & 0.51 \\
\hline interest & 519 & 21.24 & 14.57 & 13 & 1.16 & 0.36 \\
\hline pleasure & 52 & 2.13 & 1.46 & 19 & 1.70 & 0.53 \\
\hline \multicolumn{7}{|c|}{ JUDGMENT } \\
\hline \multicolumn{7}{|c|}{ social esteem } \\
\hline normality & 137 & 5.61 & 3.85 & 205 & 18.32 & 5.76 \\
\hline capacity & 289 & 11.83 & 8.11 & 332 & 29.67 & 9.32 \\
\hline tenacity & 44 & 1.80 & 1.24 & 26 & 2.32 & 0.73 \\
\hline \multicolumn{7}{|c|}{ social sanction } \\
\hline veracity & 42 & 1.72 & 1.18 & 21 & 1.88 & 0.59 \\
\hline propriety & 39 & 1.60 & 1.09 & 11 & 0.98 & 0.31 \\
\hline \multicolumn{7}{|c|}{ APPRECIATION } \\
\hline \multicolumn{7}{|l|}{ reaction } \\
\hline impact & 38 & 1.56 & 1.07 & 28 & 2.50 & 0.79 \\
\hline quality & 509 & 20.84 & 14.29 & 24 & 2.14 & 0.67 \\
\hline
\end{tabular}




\section{composition}

balance

complexity

valuation

worthwhileness
36

29

1.47

1.01

15

1.34

0.42

1.19

0.81

106

9.47

2.98

$\begin{array}{llllll}193 & 7.90 & 5.42 & 17 & 1 / 52 & 0.48\end{array}$

\section{Copyrights}

Copyright for this article is retained by the author(s), with first publication rights granted to the journal.

This is an open-access article distributed under the terms and conditions of the Creative Commons Attribution license (http://creativecommons.org/licenses/by/3.0/). 